\title{
Self-care practice and its predictors among adults with diabetes mellitus on follow up at public hospitals of Arsi zone, southeast Ethiopia
}

\author{
Rahel Nega Kassa ${ }^{1 *} \mathbb{D}$, Ibrahim Yimer Ibrahim ${ }^{2}$, Hana Abera Hailemariam ${ }^{3}$ and Mekdes Hailegebriel Habte ${ }^{4}$
}

\begin{abstract}
Objective: Diabetes mellitus is a chronic illness that requires ongoing patient self-management and support to prevent acute complications and to reduce the risk of long-term complications. The objective of the study was to assess diabetic self-care practice and its predictors among adults with diabetes mellitus on follow up at hospitals of Arsi zone, southeast Ethiopia.

Results: Above half (53.3\%) of diabetic patients had good self-care practice. Younger age (AOR: $8.95,95 \% \mathrm{Cl}$ 1.89,42.48), earning a high income (AOR: $2.495,95 \% \mathrm{Cl} 1.0,5.85$ ), having a family history of diabetes (AOR: $4.5,95 \% \mathrm{Cl}$ 1.3, 15.5), long duration since the diagnosis of diabetes (AOR: $2.14,95 \%$ Cl 1.127,4.05), not having diabetic complications (AOR: 3.87, 95\% Cl 2,7.48), and having glucometer (AOR: 4.08, 95\% Cl 1.78l, 9.33) were significantly associated factors with good diabetic self care practice. Efforts should be made to prevent complications of diabetes mellitus, to support patients who are aged and who have no glucometer at their home to promote good self-care practice. Particularly, health care providers should give special attention to newly diagnosed patients.
\end{abstract}

Keywords: Diabetes mellitus, Self-care practice, Hospital, Arsi zone, Ethiopia

\section{Introduction}

Diabetes mellitus (DM) is a chronic illness that requires continuing medical care and ongoing patient selfmanagement, education, and support to prevent acute complications and to reduce the risk of long-term complications [1-5].

International Diabetes Federation (IDF) estimated that the global diabetes prevalence in 2019 to be $9.3 \%$ (463 million people), rising to $10.2 \%$ ( 578 million) by 2030 and $10.9 \%$ (700 million) by 2045 [6]. Additionally, WHO

\footnotetext{
*Correspondence: rahelnega208@gmail.com; rahel.nega@sphmmc.edu.et ${ }^{1}$ Department of Surgical Nursing, Saint Paul Hospital Millennium Medical College, Addis Ababa, Ethiopia
}

Full list of author information is available at the end of the article estimated DM causes 3.2 million deaths per year, six deaths every minute and 8700 deaths every day [7].

A systematically reviewed study conducted in Ethiopia showed that the prevalence of diabetes in most localities of Ethiopia appears to have increased from that estimated by the IDF in 2015 that was 3.9\% [8]. Another study conducted in Ethiopia showed that almost half $(49 \%)$ of the participants had long term diabetic complication confirmed medically [9].

In contrast, patients who have adequate self-management have better outcomes, live longer, enjoy a higher quality of life, and suffer fewer symptoms and minimal complications [10-12]. That means inadequate diabetic self-management is associated with higher patient morbidity and mortality as well as increases the costs 
of medication and laboratory tests and cost in time and effort of the care providers [13].

Though several related studies were conducted in different parts of Ethiopia and identified few factors associated with diabetes self-care practice, there is no study conducted on this topic in the present study area. As a result, this study was intended to assess the diabetic selfcare practice and its predictors among adults with DM on follow up at hospitals in Arsi zone, southeast Ethiopia; The finding of the study shows the degree of the problem and contribute to bridging information gap so as to help improve the health care delivery system in terms of enhancing the diabetic self-care practice.

\section{Main text}

\section{Study area and period}

The study was conducted from April 12, to May 12, 2017at four public Hospitals (Asella referral Hospital, Arsi Robe Hospital, Abomsa Hospital and Bekoji Hospital) in Arsi zone, South East Ethiopia.

\section{Study design}

A cross-sectional study design was employed.

\section{Study population}

All sampled adult patients with diabetes who were visiting public Hospitals in Arsi zone at diabetic follow up clinic.

\section{Eligibility criteria}

Patients with diabetes aged 18 years and above who had regular follow-up for at least 6 months. Patients who were not mentally and physically capable of being interviewed were excluded.

\section{Sample size determination}

The study used single population proportion sample size determination formula. The prevalence rate of good diabetic self-care practice was taken as $76.8 \%$ [12] with the assumption of $95 \%$ confidence interval (CI) and 5\% marginal error. Adding 10\% contingency for possible nonrespondents, the final total sample size became 301 .

\section{Sampling technique}

First, the monthly flow of patients in each hospital was determined by using the patients' appointment list. The total number of patients who had a follow-up in those four hospitals was 1502 [14]. Then, every fifth patient was selected for interview by applying a systematic random sampling technique. Finally, a lottery method was used to select the first study participants.

\section{Data collection techniques and instrument}

Data were collected by using a structured questionnaire through a face-to-face interview. Clinical data about diabetes complications and comorbidities were extracted from each patient's medical chart. A Fasting Blood Sugar (FBS) test was performed for all study participants during data collection time. Eight nurses were involved in the data collection process after they had been trained about the objective of the study and how to collect data. Afan Oromo language version of the questionnaire was used for the data collection. The quality of the data was assured by using a validated questionnaire, translation, and retranslation of the questionnaire. The questionnaire was translated from the English language to Afan Oromo and back to English by another translator. Besides, the questionnaire was pretested on 15 patients with diabetes who were $5 \%$ of the total sample size, and necessary adjustments were made before its use for actual data collection.

The data collection tool incorporated three parts. Part I: includes socio-demographic characteristics, Part II: encompasses the clinical characteristics of the respondents, and Part III: consisted of the diabetic self-care domains which were adapted from Summary of Diabetes Self-Care Activities (SDSCA) [15].

\section{Data analysis}

Data were cleaned, coded, and entered into Epi info version 7 and analyzed using SPSS version 21. Descriptive statistics were computed to describe the sociodemographic and clinical characteristics of the study participants. Binary and multivariable logistic regression analysis were performed to examine the existence of a relationship between diabetic self-care practice and the independent variables listed below. A $p$ value of $<0.05$ on a binary logistic regression was considered to select candidate variables for multivariable logistic regression analysis as well as to declare a statistical significance. The results were presented in the form of text and tables.

\section{Study variables \\ Dependent variables \\ Diabetic self-care practice.}

\section{Independent variables}

Socio-demographic factors: Sex, age, marital status, educational status, religion, and monthly income.

Clinical characteristic: type of DM, type of treatment, duration of DM diagnosis, co-morbidity, and presence of complications. 


\section{Operational definition}

\section{Self-care practice}

Study participants who scored equal to or above the mean in the SDSCA were classified as having good diabetes self-care practice and those who scored below the mean were considered as having poor self-care practice.

\section{Results}

\section{Socio-demographic characteristics of respondents}

Out of 301 study participants planned for the study, 299 of them were enrolled in the study yielding a response rate of $99.3 \%$. The mean ( \pm standard deviation) age of respondents was $39 \pm 15.8$. Most (44.8\%) of the study participants attended college and above (Table 1).

Table 1 Socio-demographic characteristics of diabetic patients on followup at public hospitals of Arsi zone, southeast Ethiopia, $2017(n=299)$

\begin{tabular}{|c|c|c|c|}
\hline Variables & Category & Frequency & Percent \\
\hline \multirow[t]{2}{*}{ Sex } & Male & 183 & 61.2 \\
\hline & Female & 116 & 38.8 \\
\hline \multirow[t]{6}{*}{ Age } & $18-24$ & 63 & 21.1 \\
\hline & $25-34$ & 70 & 23.4 \\
\hline & $35-44$ & 56 & 18.7 \\
\hline & $45-54$ & 48 & 16.1 \\
\hline & $55-64$ & 37 & 12.4 \\
\hline & $\geq 65$ & 25 & 8.4 \\
\hline \multirow[t]{4}{*}{ Religion } & Muslim & 142 & 47.5 \\
\hline & Orthodox christian & 132 & 44.1 \\
\hline & Protestant & 22 & 7.4 \\
\hline & Catholic & 3 & 1.0 \\
\hline \multirow[t]{5}{*}{ Educational status } & Cannot read and write & 65 & 21.7 \\
\hline & Can read and write & 38 & 12.8 \\
\hline & Elementary & 41 & 13.7 \\
\hline & High school & 21 & 7.0 \\
\hline & College and above & 134 & 44.8 \\
\hline \multirow[t]{4}{*}{ Marital status } & Single & 86 & 28.7 \\
\hline & Married & 202 & 67.3 \\
\hline & Divorced & 7 & 2.3 \\
\hline & Widowed & 4 & 1.7 \\
\hline \multirow[t]{3}{*}{ Monthly income } & Low & 158 & 52.8 \\
\hline & Medium & 42 & 14.0 \\
\hline & High & 99 & 33.1 \\
\hline \multirow[t]{4}{*}{ Occupation } & Farmer & 162 & 54.0 \\
\hline & Private business & 55 & 18.3 \\
\hline & Student & 46 & 15.3 \\
\hline & Employed & 36 & 12.0 \\
\hline \multirow[t]{2}{*}{ Place of residence } & Urban & 130 & 43.3 \\
\hline & Rural & 169 & 56.7 \\
\hline
\end{tabular}

About half (52.8\%) of the respondents earned low monthly income whereas $67.3 \%$ of them were married.

\section{Clinical characteristics of respondents}

Majority (58.2\%) of the study participants had type 1 diabetes. Most (66.2\%) of the respondents had normal body weight $\left(18.5-24.9 \mathrm{~kg} / \mathrm{m}^{2}\right)$. A large proportion (86.9\%) of the respondents did not have a glucometer. The vast majourity $(74.9 \%)$ of the study participants had not experianced diabetic complications and $72.9 \%$ of them had no comorbidities (Table 2).

\section{Factors associated with diabetic self-care}

Overall, $53.3 \%$ of the study participants had good diabetes self-care practice. Diabetic patients aged 25-34 years were 8.95 times (AOR: $8.95,95 \%$ CI 1.89, 42.48) more likely to have good self-care practice than those who were above 65 . The odds of good diabetic self-care practice were 2.5 times (AOR: $2.5,95 \%$ CI 1.07, 5.85) higher among respondents who earned a high monthly income than those who earned lower monthly income.

Study participants who had a family history of DM were 4.5 times (AOR: 4.5, 95\% CI 1.3, 15.5) more likely to practice self-care habits than those who had no family history of DM. Respondents who were diagnosed

Table 2 Clinical characteristics of diabetic patients on follow-up at public hospitals of Arsi zone, southeast Ethiopia, 2017 ( $n=299)$

\begin{tabular}{|c|c|c|c|}
\hline Variables & Category & Frequency & Percent \\
\hline \multirow[t]{2}{*}{ Type of DM } & Type 1 & 174 & 58.2 \\
\hline & Type 2 & 125 & 41.8 \\
\hline \multirow[t]{2}{*}{ Family history } & Yes & 61 & 20.4 \\
\hline & No & 238 & 79.6 \\
\hline \multirow[t]{3}{*}{ Type of treatment } & Insulin injection & 195 & 65.4 \\
\hline & Oral antihyperglycemic & 89 & 29.9 \\
\hline & Both & 15 & 4.7 \\
\hline \multirow[t]{4}{*}{$\mathrm{BMI}\left(\mathrm{kg} / \mathrm{m}^{2}\right)$} & Underweight $(<18.5)$ & 50 & 16.7 \\
\hline & $\begin{array}{l}\text { Normal weight1 } \\
(8.5-24.9)\end{array}$ & 198 & 66.2 \\
\hline & Overweight (25-29.9) & 47 & 15.7 \\
\hline & Obese (30 and above) & 4 & 1.3 \\
\hline \multirow[t]{2}{*}{ Having glucometer } & Yes & 40 & 13.1 \\
\hline & No & 259 & 86.9 \\
\hline \multirow[t]{2}{*}{ Diabetic complications } & Yes & 85 & 25.1 \\
\hline & No & 214 & 74.9 \\
\hline \multirow{2}{*}{$\begin{array}{l}\text { Presence of comorbidi- } \\
\text { ties }\end{array}$} & Yes & 81 & 27.1 \\
\hline & No & 218 & 72.9 \\
\hline \multirow[t]{3}{*}{ Duration of diagnosis } & $<5$ & 103 & 34.4 \\
\hline & $5-10$ & 95 & 31.8 \\
\hline & $>10$ & 101 & 33.8 \\
\hline
\end{tabular}

$D M$ diabetes mellitus, $B M I$ body mass index 
before 10 years were two times (AOR: 2.14, 95\% CI $1.13,4.05)$ more likely to have self-care practice than those patients who had been less than 5 years after their DM diagnosis.

Those respondents who had no history of diabetic complications were 3.87 times (AOR: 3.87, 95\% CI $2.002,7.48)$ more likely to follow the recommended self-care practice than those patients who had diabetic complications. Study participants who had glucometer at their home were 4.077 times (AOR: 4.077, 95\% CI $1.78,9.33$ ) to perform diabetic self-care practices than those who did not have the equipment at their home (Table 3).

\section{Discussion}

This study assessed self-care practice and its associated factors among adults with DM on follow up at Public hospitals of Arsi zone. Accordingly, 46.7\% (95\% CI 40.6-52\%) of the respondents had poor self-care practices. This finding is almost in line with the studies conducted at Addis Ababa, Nekemte referral hospital, West Shoa, Benishangul Gumz Public Hospital, Hadiya Zone, Southwest Ethiopia, and the University of Gondar which were $44.4 \%, 45 \%, 45.5 \%, 45.7 \%, 47.7 \%, 50.8 \%$ and $51.86 \%$ respectively [16-22].

On the other hand, the finding in the present study was higher than the studies carried out at Dilla referral

Table 3 Factors associated with diabetic self-care practices among adults with diabetes mellitus on follow-up clinics at public hospitals of Arsi zone, southeast Ethiopia, 2017

\begin{tabular}{|c|c|c|c|c|c|}
\hline \multirow[t]{2}{*}{ Variables } & \multicolumn{2}{|c|}{ Self-care practice status } & \multirow[t]{2}{*}{ COR $(95 \% \mathrm{Cl})$} & \multirow[t]{2}{*}{ AOR $(95 \% \mathrm{Cl})$} & \multirow[t]{2}{*}{ P value } \\
\hline & Poor N\% & Good N\% & & & \\
\hline \multicolumn{6}{|l|}{ Age } \\
\hline $18-24$ & $18(12.95)$ & $45(28.13)$ & $1.500(0.593-3.791)^{*}$ & $10.44(2.76-39.5)^{* *}$ & 0.001 \\
\hline $25-34$ & $35(25.2)$ & $35(21.9)$ & $3.750(1.423-9.883)^{*}$ & $8.95(1.89-42.48)^{* *}$ & 0.006 \\
\hline $35-44$ & $27(19.42)$ & $29(18.13)$ & $2.611(0.619-4.193)^{*}$ & $7.24(1.67-31.32)^{* *}$ & 0.008 \\
\hline $45-54$ & $24(17.3)$ & $24(15)$ & $1.500(0.563-3.997)$ & $3.39(0.75-15.27)$ & 0.113 \\
\hline $55-64$ & $20(14.4)$ & $17(10.63)$ & $1.275(0.456-3.567)$ & $2.203(0.48-10.16)$ & 0.311 \\
\hline$\geq 65$ & $15(10.8)$ & $10(6.25)$ & 1 & 1 & \\
\hline \multicolumn{6}{|c|}{ Marital status } \\
\hline Single & $30(21.6)$ & $56(35)$ & $1.87(1.198-2.908)$ & $1.1(0.49-2.40)$ & 0.855 \\
\hline Married & $104(74.8)$ & $98(61.25)$ & $.942(.715-1.242)$ & $1.3(0.20-9.40)$ & 0.824 \\
\hline Divorced & $2(1.44)$ & $5(3.13)$ & $2.5(.485-12.889)$ & $0.3(0.02-4.03)$ & 0.347 \\
\hline Widowed & $3(2.16)$ & $1(0.625)$ & 1 & 1 & 1 \\
\hline \multicolumn{6}{|c|}{ Monthly income } \\
\hline Poor & $71(51.1)$ & $87(54.4)$ & 1 & 1 & \\
\hline Medium & $17(12.2)$ & $25(15.6)$ & $1.081(0.569-2.054)$ & $1.563(0.839-2.912)$ & 0.160 \\
\hline Rich & $51(36.7)$ & $48(30)$ & $3.409(1.684-6.898)^{*}$ & $2.495(1.07-5.85)^{* *}$ & 0.035 \\
\hline \multicolumn{6}{|c|}{ Family history of DM } \\
\hline Yes & $15(10.79)$ & $46(28.75)$ & $3.282(1.737-6.201)^{*}$ & $4.49(1.3-15.466)^{* *}$ & 0.017 \\
\hline No & $124(89.21)$ & $114(71.25)$ & 1 & 1 & \\
\hline \multicolumn{6}{|c|}{ Duration of diagnosis (years) } \\
\hline$<5$ & $52(37.41)$ & $50(31.25)$ & 1 & 1 & \\
\hline $5-10$ & $50(35.97)$ & $45(28.13)$ & $0.567(0.324-0.992)$ & $0.96(0.511-1.801)$ & 0.897 \\
\hline$>10$ & $37(26.62)$ & $65(40.62)$ & $0.520(0.294-0.921)^{*}$ & $2.14(1.127-4.05)^{* *}$ & 0.020 \\
\hline \multicolumn{6}{|c|}{ Diabetic complication } \\
\hline Yes & $32(23)$ & $53(33.1)$ & 1 & 1 & \\
\hline No & $107(77)$ & $107(66.9)$ & $2.634(1.502-4.621)^{*}$ & $3.87(2.002-7.48)^{* *}$ & 0.001 \\
\hline \multicolumn{6}{|c|}{ Presence of glucometer } \\
\hline Yes & 130(93.5) & 129(80.6) & $3.905(1.73-8.82)^{*}$ & $4.077(1.78-9.33)^{* *}$ & 0.001 \\
\hline No & $9(6.5)$ & $31(19.4)$ & 1 & 1 & \\
\hline
\end{tabular}

COR crude odds ratio, $A O R$ adjusted odds ratio, $C l$ confidence interval

*P value $<0.05$

**Shows statistically significant association 
hospital, Iran, Debre Tabor General Hospital, and west Ethiopia where only $23.2 \%, 26.2 \%, 36.9 \%$, and $39.3 \%$ of the study participants had poor self-care practice respectively [23-26]. Lesser access to diabetes selfcare-centered information in the present study setting, the difference in lifestyle and source of the population might be the reason for the variation since some of the previous studies included type 2 DM patients only.

On the contrary, the finding of this study was lower compared to the studies conducted in Kenya, Harari, Felegehiwot, and Ayder Comprehensive Specialized Hospitals where $59 \%, 60.8 \%, 63.2 \%$, and $74.5 \%$ of the study participants had poor self-care practice respectively [27-30]. The variation might be the presence of cross-cultural habits and variation in lifestyle of the respondents. The difference in source population and study setting might have also part of the deviation of this finding. The study participants enrolled in the present study were patients with DM who had a follow-up in a diabetic clinic whereas the study which was conducted in Kenya was at a community setting which could result in poor self-care practice as lack of information on diabetes self-care practices that comes from the clinical setting.

This study revealed that the younger age group was 8.95 times more likely to have good self-care practice than those above 65 . This finding was in line with the study conducted at Nekemt Referral Hospital and Egypt $[17,31]$. The reason for this finding could be young age which gives chance to get a healthy diet and perform regular physical exercise easily than those who are aged.

The odds of good diabetic self-care practice were 2.5 times higher in respondents who earned high monthly income than those who earned low monthly income. This finding is comparable with the study conducted in Gondar, Ayder Comprehensive Specialized Hospital, and India $[22,30,32]$. This might be due to the fact that diabetes patients who earn a high monthly income could afford to get diets that are recommended for DM patients and can also buy glucometer to monitor self-blood glucose level.

On the other hand, study participants who had a family history of DM were 4.5 times more likely to practice self-care habits than those who had no family history of DM. This could be because of experience sharing among family members.

Respondents who had a long duration of diagnosis were two times more likely to have good self-care practice than those patients with a short duration of a diabetes diagnosis. This study is in line with the studies conducted in West Shoa, Iran, and west Ethiopia [18, 24, 26]. The best reason for good self-care practice in patients with a long duration of diagnosis could be due to more contact with health care providers that may benefit them to get regular counseling and help improve self-care practices.

Those respondents who had no diabetic complications were 3.87 times more likely to follow the recommended self-care practice than those patients who had diabetic complications. This finding was congruent with the study conducted at the University of Gondar Referral Hospital [22]. This could be due to the fact that patients who had not developed complications could care for themselves easily.

Study participants who had a glucometer at their home were 4.077 more likely to perform diabetic self-care practices than those who did not have a glucometer. The finding in this study is in line with the study conducted at Benishangul Gumz Public Hospitals, Hadiya zone, and Debre Tabor General Hospital [19, 20, 25]. The possible reason might be having a glucometer could give chance to have regular self-blood sugar measurement and result in better metabolic control.

\section{Conclusion}

The finding of this study revealed that a substantial number $(46.7 \%)$ of respondents had poor diabetic selfcare practice. Efforts should be made in the prevention of complications and concerning bodies should support those patients who are, aged, earning low monthly income, and who do not have glucometer at their home. Particularly, health care providers should give special attention to newly diagnosed patients.

\section{Limitation}

The use of self-report of the study participants about selfcare practice than direct observation was the limitation of the study which could result in social desirability bias.

\section{Abbreviations \\ AOR: Adjusted odds ratio; BMI: Body mass index; Cl: Confidence interval; COR: Crude odds ratio; DM: Diabetes mellitus; Epi info: Statistical Package for epi- demiological information analysis; FBS: Fasting blood sugar; IDF: International diabetes association; SDSCA: Summary of diabetic self-care activities; SPSS: Statistical package for social science; WHO: World Health Organization; ETB: Ethiopian Birr.}

\section{Acknowledgements}

We would like to thank Arsi University, School of Health Sciences for the support of necessary materials while doing this study. We also like to thank the hospital administrators, data collectors, and study participants.

\section{Authors' contributions}

RN generated the research idea, designed and implementation of the study, wrote the proposal, participated in data collection, carried out statistical analysis and wrote the manuscript. IY, HA, and $\mathrm{MH}$ approved the proposal with revisions, participated in drafting, writing, reviewing, and approval of the manuscript for publication. They were actively involved in the interpretation of the data. All authors read and approved the final manuscript.

Funding

No financial support was gained to conduct the study. 


\section{Availability of data and materials}

To keep patients'confidentiality, the raw data would not be shared. But, it is available from the corresponding author on reasonable request.

\section{Declarations}

\section{Ethics approval and consent to participate}

The study was approved by the Ethical Review of College of health sciences of Arsi University (Ref.no: CHS/R/0018/2016/17). Permission was obtained from Arsi zone health bureau to access hospitals. Written consent was obtained from each study participant after explaining the objectives of the study and data collection procedures. The right of study participants not to participate in the study was assured.

\section{Consent for publication}

Not applicable.

\section{Competing interests}

The authors declare that they have no competing interests.

\section{Author details}

1 Department of Surgical Nursing, Saint Paul Hospital Millennium Medical College, Addis Ababa, Ethiopia. ${ }^{2}$ Ethiopian Midwives Association, Addis Ababa, Ethiopia. ${ }^{3}$ Department of Neonatal Health Nursing, Saint Paul Hospital Millennium Medical College, Addis Ababa, Ethiopia. ${ }^{4}$ Department of Pediatrics Nursing, Saint Paul Hospital Millennium Medical College, Addis Ababa, Ethiopia.

\section{Received: 2 November 2020 Accepted: 4 March 2021}

Published online: 19 March 2021

\section{References}

1. Standards of medical care. J Clin Appl Res Educ Diabetes care. 2015; 38(supplement).

2. American Diabetes Association. Standards of medical care in Diabetes. J Clin Appl Res Educ. 2016; 39(supp1).

3. Shrivastava SR, Shrivastava RS, Ramsamy J. Role of self-care in management of diabetes mellitus. J Diabetes Metab Disord. 2013; 12:14. http:// www.jdmdonline.com/content/12/1/14.

4. Lyndon S, Gopichandran V, Angel MK, Manayalil BP, Blessy KR, Alex RG, Kumaran V, Balraj V. Diabetes self-care activities a community-based survey in urban southern India. Nat Med J India. 2012;25:1.

5. American Diabetes Association. Standards of medical care in diabetes. Strateg Improv Diabetes Care. 2016;39(1):S6-12.

6. Saeedi P, Petersohn I, Salpea P, Malanda B, Karuranga S, Unwin N, Colagiuri S, Guariguata L, Motala AA, Ogurtsova K, Shaw JE, Bright D, Williams R; IDF Diabetes Atlas Committee. Global and regional diabetes prevalence estimates for 2019 and projections for 2030 and 2045: Results from the International Diabetes Federation Diabetes Atlas, 9th edition. Diabetes Res Clin Pract. 2019;157: https://doi.org/10.1016/j.diabres.2019.107843.

7. World Health Organization. Definition, diagnosis and classification of diabetes mellitus and its complications. 2007.

8. Abebe N, Kebede T, Addise D. Diabetes in Ethiopia 2000-2016-prevalence and related acute and chronic complications; a systematic review. Afr J Diabetes Med. 2017;25:2.

9. FelekeY EF. An assessment of the health care system for diabetes in Addis Ababa, Ethiopia. Ethiopian J Health Dev. 2000;19:3.

10. Temesgen TG, Shiferaw A, Belayneh KG, Amsalu DD, Minyahil A. Glycemic control and self-care practice among ambulatory diabetic patients in Ambo general hospital, west Showa, Ethiopia. Glob J Med Res. 2014;14:7.

11. American Diabetes Association. National standards for diabetes selfmanagement education diabetes care. 2007;30(supplement1).

12. Addisu $Y$, Eshete A, Hailu E. Assessment of diabetic patient perception on diabetic disease and self-care practice in Dilla university referral hospital, south Ethiopia. J Metab Synd. 2013;3:4

13. Abebe SM, Berhane Y, Worku A, Assefa A. Diabetes mellitus in north west Ethiopia: a community based study. BMC Public Health. 2014;14:97.

14. Arsi zone health office. Annual health report of the zone. 2016.
15. Toobert DJ, Hampson SE, Glasgow RE. The summary of diabetes self-care activities measure: results from 7 studies and a revised scale. Diabetes Care. 2000;23(7):943-50

16. Bongar Z, Shiferaw S, Zerihun E. Adherence to diabetic self-care practices and its associated factors among patients with type 2 diabetes in Addis Ababa, Ethiopia. Patient Prefer Adherence. 2018;12:963-70.

17. Amente T, Belachew T, Hailu E, Berhanu N. Self-care practice and its predictors among adults with diabetes mellitus on follow up at Nekemte hospital. World J Med Med Sci. 2014:2(3):1-16.

18. Gurmu Y, Gela D, Aga F. Factors associated with self-care practice among adult diabetes patients in West Shoa zone, Oromia regional state, Ethiopia. BMC Health Serv Res. 2018;18:732.

19. Chali WS, Salih HM, Abate AT. Self-care practice and associated factors among diabetes mellitus patients on follow up in Benishangul Gumuz regional state public hospitals, western Ethiopia: across-sectional study. BMC Res Notes. 2018;11:833.

20. YilimaTesfaye CDFG, BirukWT. Predictors of diabetes self-care practice and associated factors among patient on follow up at Hadiya zone, health institutions southern Ethiopia, using health belief model, crosssectional study design. EC Endocr Metab Res. 2019:4(10):01-17.

21. Kassahun T, Gesesew H, Mwanri L, Eshetie T. Diabetes related knowledge, self- care behaviours and adherence to medications among diabetic patients in southwest Ethiopia: a cross-sectional survey. BMC Endocr Disord. 2016;16:28.

22. Aschalew AY, Yitayal M, Minyihun A, Bisetegn TA. Self- care practice and associated factors among patients with diabetes mellitus on follow up at university of Gondar referral hospital, Gondar, northwest Ethiopia. BMC Res Notes. 2019;12:591.

23. Addisu Y, Eshete A, Hailu E. Assessment of diabetic patient perception on diabetic disease and self-care practice in Dilla university referral hospital, south Ethiopia. J Metabolic Synd. 2014;3:166. https://doi.org/10.4172/ 2167-0943.1000166.

24. Yekta Z, Pourali R, Aghassi MR, Ashragh N, Ravanyar L, Rahim Pour MY. Assessment of self care practice and its associated factors among diabetic patients in urban area of Urmia, northwest of Iran. J Res Health Sci. 2011:11(1):33-8.

25. Tiruneh SA, Ayele AA, Emiru YK, Tegegn HG, Ayele BA, Engidaw MT, Gebremariam AD. Factors influencing diabetes self care practice among type 2 diabetes patients attending diabetic care follow up at an Ethiopian general hospital, 2018. J Diabetes Metab Disord. 2019;18(1):199-206. https://doi.org/10.1007/s40200-019-00408-z

26. Dedefo MG, Ejeta BM, Wakjira GB, Mekonen GF, Labata BG. Self-care practices regarding diabetes among diabetic patients in west Ethiopia. BMC Res Notes. 2019;12:212.

27. Kiberenge MW, Ndegwa ZM, Njenga EW, Muchemi EW. Knowledge, attitude and practices related to diabetes among community members in four provinces in Kenya: a cross-sectional study. Pan Afr Med J. 2010;7:2.

28. Ayele K, Tesfa B, Abebe L, Tilahun T, Girma E. Self care behavior among patients with diabetes in Harari, eastern Ethiopia: the health belief model perspective. PLOS ONE. 2012;7(4):e35515. https://doi.org/10.1371/journal. pone.0035515

29. Feleke SA, Alemayehu CM, Adane HT. Assessment of the level and associated factors with knowledge and practice of diabetes mellitus among diabetic patients attending at FelegeHiwot Hospital, northwest Ethiopia. Clin Med Res. 2013;2(6):110-20. https://doi.org/10.11648/j.cmr.20130206. 11.

30. Niguse H, Belay G, Fisseha G, Desale T, Gebremedhn G. Self-care related knowledge, attitude, practice and associated factors among patients with diabetes in Ayder comprehensive specialized hospital, north Ethiopia. BMC Res Notes. 2019;12:34.

31. Mahfouz EM, Awadalla HI. Complaince to diabetes self-care management in rural El-Minia, Egypt. Cent Eur J Public Health. 2011;19(1):35-41.

32. Suguna A, Magal AS, Stany A, Sulekha T, Prethesh K. Evaluation of self-care practices among diabetic patients in a rural area of Bangalore district, India. Int J Curr Res Aca Rev. 2015;3:415-22.

\section{Publisher's Note}

Springer Nature remains neutral with regard to jurisdictional claims in published maps and institutional affiliations. 